\title{
The Molecular Basis of Neural Memory: Part 8. Case Studies of "Neuro-mimetic" Technologies
}

\author{
Gerard Marx* and Chaim Gilon \\ MX Biotech Ltd., Israel \\ Institute of Chemistry, Israel \\ *Corresponding author: Gerard Marx, MX Biotech Ltd., Jerusalem, Israel
}

Submission: 眥 November 15, 2018; Published: 制 November 21, 2018

\begin{abstract}
From Cajal's [1] original studies ( 1900), neurobiologists have represented neurons as "naked", seemingly suspended in "space". Cajal [1] overlooked issues relevant to the emergence of the memory talent from neural nets, specifically:
\end{abstract}

1. Not recognizing the morphology of the biologic neuron as relevant to its memory function.

2. Ignoring the presence of extracellular matrix (nECM), a hydrogel web/lattice entangling the extended neuron.

3. Unawareness of non-synaptic signaling between neurons through the nECM.

4. No code for emotions.

We review 2 technologies, the IBM Brain Chip and the Blue Brain Project, both which are flawed by the same oversights.

To address these flaws, we propose a tripartite mechanism, based on the dynamic interactions of 3 compartments:

1) Neurons-including glia cells/astrocytes

2) Neural extracellular matrix (nECM), a hydrogel synthesized by, and surrounding, the neurons, which performs as a "memory material".

3) Dopants (metals + neurotransmitters (NTs)) released into the nECM, employed by the neuron to encode cognitive information with emotive context.

Effectively, this mechanism provides a psycho-chemical explanation of the encoding of emotive neural memory.

Awareness of the nECM around neurons and a molecular code for emotions, missing in both the IBM chip and the Blue Brain simulation, could lead to better modeling of mentation processes relating to neural memory. It could also aid the development of "neuro-mimetic" devices and simulations truer to neuro-biology and neuro-chemistry.

Keywords: Mentation; Emotion; Neurotransmitters; Metal complexes

\section{Introduction}

You have to begin to lose your memory, if only in bits and pieces, to realize that memory is what makes our lives. Life without memory is no life at all, just as an intelligence without the possibility of expression, is not really an intelligence. Our memory is our coherence, our reason, our feeling, even our action. Without it, we are nothing. Human memory is a marvelous but fallacious instrument. The memories which lie within us are not carved in stone; not only do they tend to become erased as the years go by, but often they change, or even increase by incorporating extraneous features.

Though much considered, memory remains a "mystery of mysteries". The talent of the brain's neural net to recall past events, is of great interest to the general public as well as to cognitive scientists, witness the many articles in the popular press, high quality books and movies [2-9], as well as many religious tracts (not cited, but voluminous) and scientific literature (some cited below). We are nothing without memory.

How do we remember anything? or phrased more scientifically: What is the physiologic mechanism underlying the expression of neural memory?

In that computers are our only artifacts which exhibit the recall function, one is prone to equate memory processes occurring in our brain with those of computers. Below, we examine this supposition.

\section{Historical Background}

"Myopia" can be defined as not being able to focus on what's in front of you. From Cajal's [1] original histological studies ( 1900), most workers continued to represent neurons as "naked", suspended in space (Figure 1A), ignoring the surrounding neural extracellular matrix (nECM) that envelops them, which was called "perineural 
net" (PNN) by Golgi but ignored by Cajal [1] as a "histologic artifact" $[1,10-13]$. In the 1950 's, the actuality of the nECM was clarified by biochemical characterization, later by immuno-staining and electron microscopic (SEM, TEM) techniques [14-21]. But to this day, the $\mathrm{nECM}$ is not considered to serve a memory function analogous to the inorganic matrix in computer memory chips [22]. Cajal's [1] "conceptual myopia" regarding the nECM has been repeated by subsequent generations of neurobiologists; "group myopia" exemplified in Figure 1A \& 1B, corrected in Figure 1C.

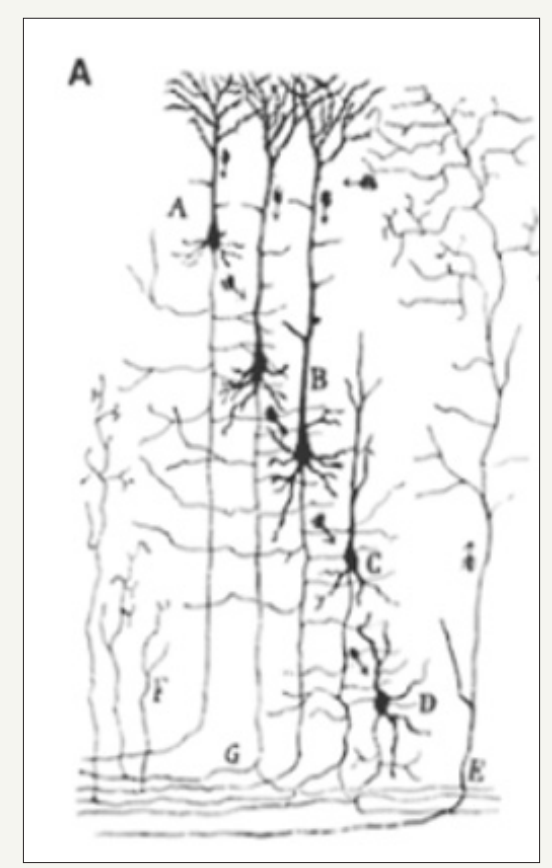

Figure 1A: Early drawings made by Cajal [1] in order to illustrate his views of the circuitry of the cerebral cortex (from Jones 12). Note the emptiness around the neurons.

B.

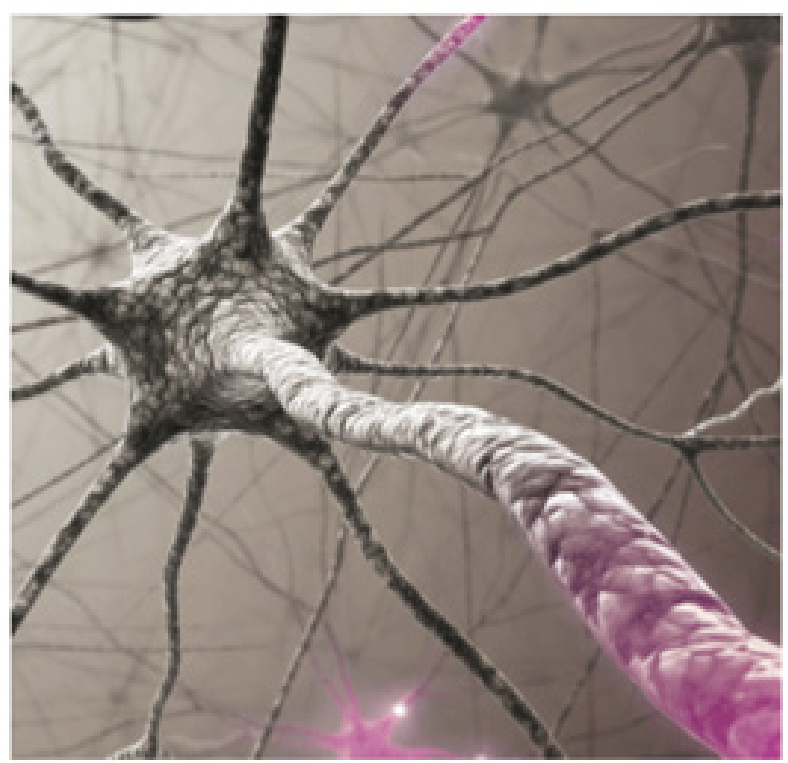

C.

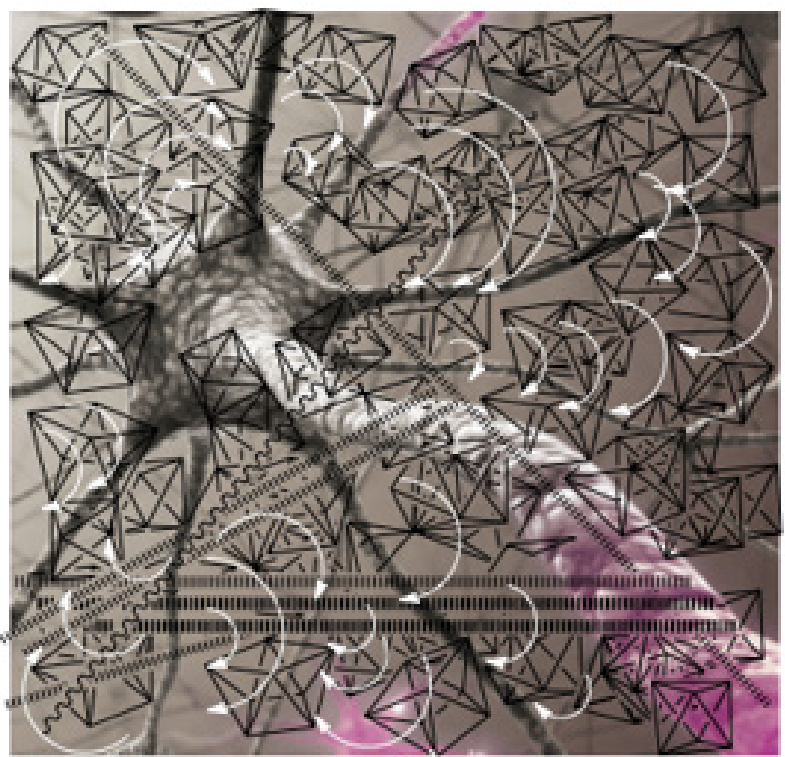

Figure 1B: Modern photomicrograph of "naked neurons", as if suspended in space (from a Nov 4, 2011 cover from Science, with permission AAAS). A number of similar (not shown) images have appeared in various issues of Science (342: 917 (2013); $349: 575$ (2015); 350: October 2015 (cover); 334: November 2011 (cover), as well as in Nature Neuroscience (August 2010)).

Figure 1C: Corrected neurons from panel B with added schematic representations of the nECM lattice and proteins (as white lines, and black shapes), enveloping the neurons, through which non- synaptic electro- and chemo-dynamic signaling occurs. 


\section{A. McCullogh \& Pitts}

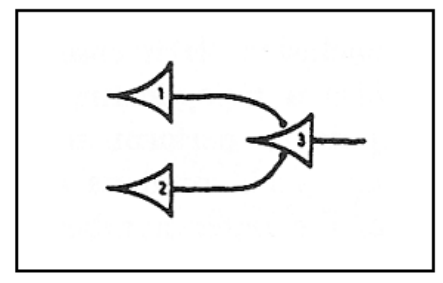

B. Tripartite

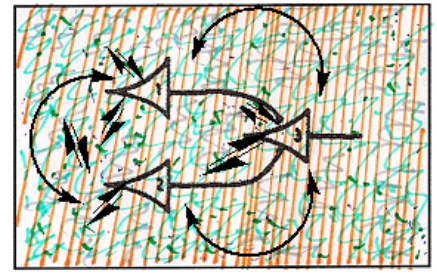

EF $\mathrm{nECM}+$ dopants

signaling

Figure 2: Schematic representations of neural net signaling:

A: A "Cajalian" circuit, schematic neurons insulated in "space", with uni-directional synaptic signal (i.e. "naked neurons") (from McCullogh, 24). (get permission).

B: Corrected Tripartite neural circuit, where the "neurons" are not "naked", but intimately surrounded by nECM through which they signal via non-synaptic modalities, also termed "volume transmission" [24-27].

A consequence of Cajal's [1] ignoring the implications of the neuron's extended shape (with much surface area), was reflected by McCullogh \& Pitts very influential representations of monodirectional signaling by neural nets (Figure 2A \& 2B) [23-27].

It is of historical interest that McCullogh [28b] model of the signaling biologic neuron was useful (to von Neumann) in developing a concept of silicon-based microprocessor signalling $[28,29]$, on which modern computers are based. It is also the basis on which new technologies, touted as being "neuro-mimetic", are being developed (IBM Brain Chip and Blue Brain Project discussed below). A comparison of computer memory with the neural memory reveals the deep differences (Table 1).

Table 1: Comparing memory processing.

\begin{tabular}{|c|c|c|}
\hline Item & Computer & Brain \\
\hline Processing unit & Ionic memory chip & Neuron (with glia cell) \\
\hline Information theory & $\begin{array}{l}\text { Boole, Turing, McCullogh \& Pitts, von Neumann, } \\
\text { Shannon, Wiener, et al }\end{array}$ & Cajal, Hopfied, Hebb, Kandel, et al. \\
\hline Information unit & Bit, Qubit & Cuinfo \\
\hline Matrix composition & Dry silicon oxide & Wet biopolymer gel \\
\hline Construction & Static hardwiring & Dynamic (growth/decay) \\
\hline Architecture & $2 \mathrm{D}$ & 3D \\
\hline Dopant(s) & 1 element metal & $>10$ elemental metals \\
\hline \multicolumn{3}{|c|}{$>90$ neurotransmitters (NTs) } \\
\hline Format & Digital & Analogue \\
\hline Read/write & $\begin{array}{l}\text { Voltage differentials, Optical signals, magnetics } \\
\text { effects }\end{array}$ & $\begin{array}{l}\text { Allosteric binding/chemo-dynamic vesicle } \\
\text { release }\end{array}$ \\
\hline Programming mode & Serial $_{2}$ & Parallel \\
\hline Groupings & Dedicated circuits & Anatomic units, sparse set of neurons \\
\hline Underlying physics & Electro magnetic & Electro- and chemo-dynamic \\
\hline Signal speed & c (speed of light) & $1-80 \mathrm{~m} / \mathrm{s}$ \\
\hline Calculations/see & $>10^{+6}$ (FLOPS, MIPS) & 200 \\
\hline Signal frequency & $50-60 \mathrm{~Hz}$ & $2-30 \mathrm{kHz}$ \\
\hline Energy & External (250mWatts) ${ }^{*}$ & Metabolism (20watts), 400cal/day \\
\hline Encoding values & $2(0,1)$ & $>10$ \\
\hline Encoding type & Logical & Emotive + Logical (in some) \\
\hline
\end{tabular}


Clearly, the computer is an inappropriate model of the brain In this vein and in spite of the adoption of the term "neural net", we consider two contemporary examples of computer-based technologies, purported to mimic the workings of a biological neural net.

\section{Case Study I}

\section{IBM's brain biochip}

The IBM "Brain Biochip" proposes that a (silicon) chip, with (copper) electronic circuits exhibiting built-in gaps (i.e. synapses), is equivalent to a neuron network [30-32]. But we question the conceptualization as well as the presentation of this chip.

Under the guise of "inspiration", the artwork suggests neurons growing on circuit wiring. The chip fabricators appropriate the language of neurobiologists, by using terms like "neuron" and "synapse" to refer to electronic constructs and models that are not true to biology, as in Figure 3A. Neurons cannot grow or be attached directly onto copper circuits. In general, cells cannot can grow on copper...it is toxic. Copper-based paints are used to paint the hulls of ships, to prevent algae or barnacle attachment. Copper is toxic to cell cultured mammalian cells.

Even were viable cells to be soldered onto the chip, as per Figure 3A, they would require cell culture conditions (wet, aeration, etc) to remain viable. Thus, there is confusion. A biochip based on a wet, cell culture construct merged with an electronic device would not be technically feasible. The underlying conceptual issues are illustrated (Figure $3 \mathrm{~A}-\mathrm{C}$ ).

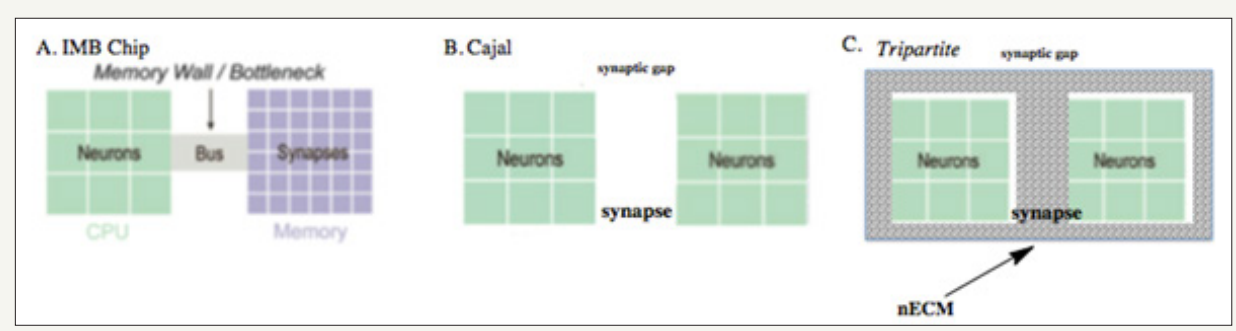

Figure 3A: IBM schematic of their Brain chip. The "memory repository", a piece of microprocessor, arbitrarily called "synapse", is connected to a single "neuron" by a "bus" (ref [30], with permission AAAS). This is far from a biologic model of neural organization. Figure 3B: A "Cajalian" schematic of a pair of abstract "neurons.". Note that Cajal's synapse defines the gap between the two distinct "neurons". The surroundings are ignored.

Figure 3C: A tripartite schematic of a pair of abstract "neurons" and the "synapse" between them (like Cajal's), within an enclosing gray box, representing the nECM + dopants (metals + neurotransmitters (NTs)) surrounding the pair of neurons and the intervening synapse.

\section{Critique}

The "brain-inspired biochip" illustrated on the cover of Science (Figure 2) became transformed into a "brain biochip" in the news stories covering the scientific article [31,32]. The drawing represents imagined neural shapes anchored to an electronic silicon/copper circuit by soldered contact points. There is no indication of the hydrogel in which biological neurons are encased. Recall that electronic circuits are usually isolated from their surroundings by non-conducting air or space, not water.

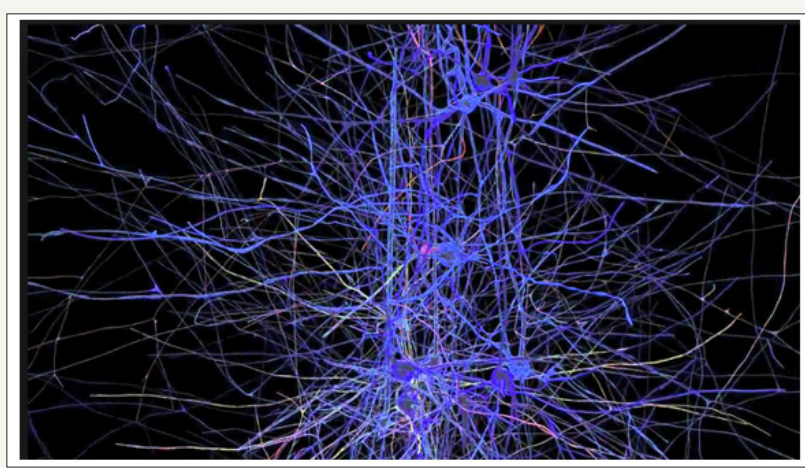

Figure 4: One of the images presented at the Blue Brain site. Note that the neurons are rendered as if they were surrounded by empty space (with permission Blue Brain Project).

The Supplement section of that article provided schematic diagrams of microprocessor circuits /transistors located within a discrete rectangular region of the chip termed a "neuron"; and a nearby rectangular region performing as a repository for memory, arbitrarily termed a "synapse" (Figure 3). Moreover, it ignores that neurons are capable of signaling one another via nonsynaptic channels through the nECM (ephaptic signaling, volume transmission, [25-27]).

The appropriation of neuro-biologic terms ("neuron", "synapse", "neural network") to represent electronic chip regions, clarifies neither the chip's processing procedure nor that of the biologic neuron, which it purportedly attempts to mimic. The text accompanying these renderings use words like "neuromorphic" and "synapse" to suggest direct paralells to biologic neural nets. But the schematic chip's "synapse" compartment (Figure 3B) has neither morphologic nor conceptual resemblance to the gap between two biologic neurons suspended in nECM, signaling one-another; an example of "linguistic plasticity".

Similar critiques could be aimed at other projects, which describe themselves with terms such as "neuromorphic" or "computational neuroscience" [29-33]. The term "artificial neural network" is particularly misleading, as it is based on a model whereby "naked" neurons communicate with one another exclusively through synaptic signals. But we and others have previously pointed out that neurons are not "naked", but encased in nECM and participate in non-synaptic signaling (see above citations).

How to cite this article: Gerard Marx, Chaim Gilon. The Molecular Basis of Neural Memory: Part 8. Case Studies of "Neuro-mimetic" Technologies. Res Med Eng Sci. 7(1). RMES.000651. 2018. DOI: 10.31031/RMES.2018.07.000651 
In spite of these misconceptions, IBM's "Brain Chip" garnered a great deal of publicity and mention as a runner-up in Science "Breakthrough of the Year 2014".

\section{Case Study II}

\section{Blue Brain Project}

The Blue Brain Project [34-39] aims to emulate the workings of a biologic neural net with IBM's deep blue super-computer. Confidence in this approach is based on the abilities to "simulate some of nature's most intimate processes", like:
a) Protein folding
b) Gene networks
c) Opening/closing ion channels on cell surfaces

Facts: A supercomputer is one with a high-level computational capacity. IBM's blue gene/P supercomputer at Argonne National Laboratory runs over 250,000 processors cooled by air conditioning, grouped in 72 racks/cabinets connected by a high-speed optical network ( $>200$ watts to run).

Performance of a supercomputer is measured in floating-point operations per second (FLOPS) instead of million instructions per second (MIPS). As of 2015, there are supercomputers which can perform up to quadrillions of FLOPS (from Wikipedia). The human brain runs on $\sim 200 \mathrm{cal} /$ day with memory capacity estimated as being organized from 1011 neurons each with 103 synaptic connections, on the order of 100 trillion "data points" (100 Terabytes) [36-38]. As pointed out above, the brain's neurons are not "naked". Rather they are surrounded by a hydrogel lattice wherein small molecules (metals and neurotransmitters (NTs)) diffuse and through which non-synaptic (ephaptic) signaling occurs.

Critique: The purported aim of the Blue Brain project [34$39]$ and other similarly aimed efforts $[40,41]$, is "to place neurons in their natural environment- with other neurons". Based on a questionable Cajalian neural model of synaptic, unidirectional signaling, deep blue purports that "a fundamentally different form of intelligence will emerge". The success of this approach has been questioned [38,39].

We additionally point out that the Blue Brain simulation ignores the key aspects of neural biology, namely:

1. Morphology: The highly extended neurons (all types) are all encased in nECM. To recognize neural morphology and the reality of the nECM; cell shape is revelatory and the biochemistry of nECM has been documented (citations above). There are no "naked neurons".

2. Emotions: Biologic neural nets experience emotions, which are totally absent in computers such as Deep Blue, which cannot encode emotions for which there is no binary code.

These oversights are insurmountable obstacles to the stated goals of the Blue Brain Project.

\section{Discussion}

Telling quotes regarding artificial neural nets and intelligence [9] reveals the problem:

"Neural network software is used to simulate, research, develop, and apply artificial neural networks, software concepts adapted from biological neural networks, and, in some cases, a wider array of adaptive systems such as artificial intelligence (AI) and machine learning.

“...artificial neural networks (ANNs) are a family of statistical learning algorithms inspired by biological neural networks (the central nervous systems of animals, in particular the brain).

"Commonly used artificial neural network simulators include the Stuttgart Neural Network Simulator (SNNS), Emergent, JavaNNS, Neural Lab and NetMaker."

The linguistic transformation of "simulated neural nets" into "neural nets", is fraught with misunderstanding, as it presumes a correspondence between the artifactual simulations of neurons and the biologic neurons of the viable brain. For example, a number of microprocessor chips have been developed with the aim of mimicking biological neural nets, confusingly referred to as "neural nets" or "neuromorphic systems" instead of "simulated devices" or "microprocessor nets". The microprocessors generally perform marvelously in terms of speed for processing logical algorithms. Their success has been demonstrated in beating human champion players of chess and go [41].

Associated groups use the terms "neural networks" and provide schematics of such, that are not true to biology. For example, the schematic of Figure 5A purports to represent an "artificial neural network" but represents the neurons as round discs floating in space, only connected by "synaptic connectors". It neglects the region around these discs, which in real neurons is actually the nECM. It also ignores non-synaptic signaling via neurotransmitters, (Table 2) as represented in the corrected Figure 5B.

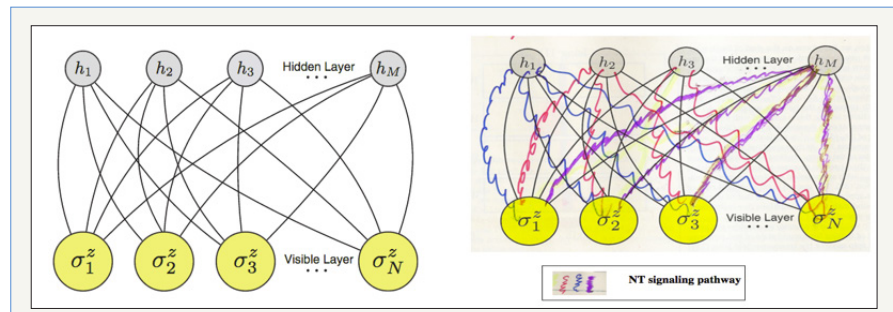

Figure 5A: A 2D representation of an "artificial neural network". It leaves out the surroundings of actual neurons and does not refer to non-synaptic signaling (with permission AAAS, ref [45]).

Figure 5B: A "corrected" schematic indicating non-synaptic signaling via NTs, a projection of a 3D system.

The repeated use of the term "neuron" appended to other phrases simply befuddfles the reader. Adoption of a term "affective computing" [42-51], does not mean that one has the means for encoding into robotic devices, the emotions experience by neural 
creatures. By similar logic, the term "neural computation" in robotics [47-50] is misleading, in that neurons neither compute nor store memory in binary format; they mentate and recall in multinary modes, as outlined below.

The term "memory $\mathrm{T}$ cells" has been applied to describe immune-competent $\mathrm{T}$ cells that either circulate or remain static, which become primed by a presented antigen, and pass along this antigenic sensitivity to subsequent generations of $\mathrm{T}$ cells [51-53]. Here, the term "memory" is relates only to immuno-competency, not to any mental process.

\section{Tripartite mechanism}

We have proposed [54-58] a tripartite mechanism of neural emotive memory, based on the dynamic interactions of 3 compartments of the brain namely:

\section{Neurons}

2. Neural extracellular matrix (nECM) surrounding neurons

3. Dopants (metals + neurotransmitters (NTs)) released into the $\mathrm{nECM}$

Memory is a talent that distinguishes neurons from other cells. The neurons (including astrocytes, glial cells) synthesize a surrounding $\mathrm{nECM}$, which they employ as a "memory material" analogous to the matrix of computer chips [22], with metals and NTs as effectors of the neural code, to form metal-centered complexes embodying cognitive units of information (cuinfo) (singular/ plutal). Metal-centered complexes have been described many times in the past, notably as catalysts for various reactions and recently described as "molecular knots" [59]. The NTs elicit physiologic responses entangled with psychic, emotive states, which are remembered. The tripartite mechanism provides a chemo-graphic perspective to the phenomenon of emotive memory, consonant with the morphology of the neuron and materials available to it (Figure 6).

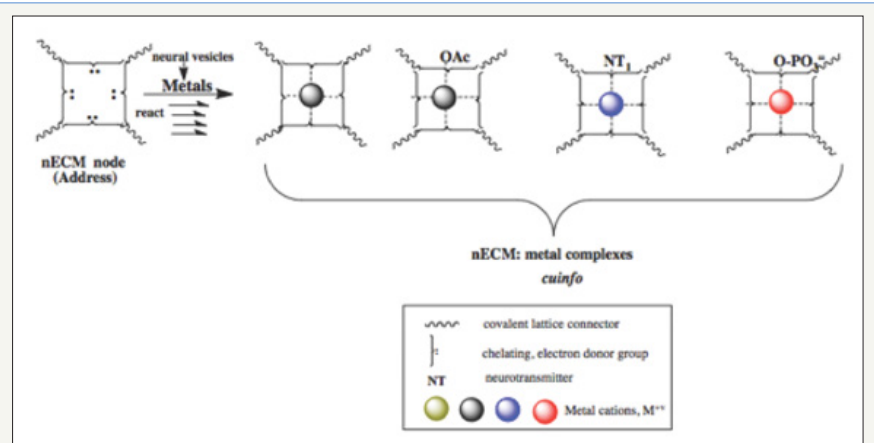

Figure 6: "Chemographic" representations of an nECM "address" encoded as cuinfo (singular/ plural) by binding a metal, with an additional derivatization tag (such as phosphate or sulfate), as well as a neurotransmitter (NT), the coding signifier of a "feeling", recalled as "emotion".

In search of well characterized models of such metal complexes, we reproduce a recently published image of the structures synthesized with metals interacting with polydendate molecular ensembles (Figure 7).

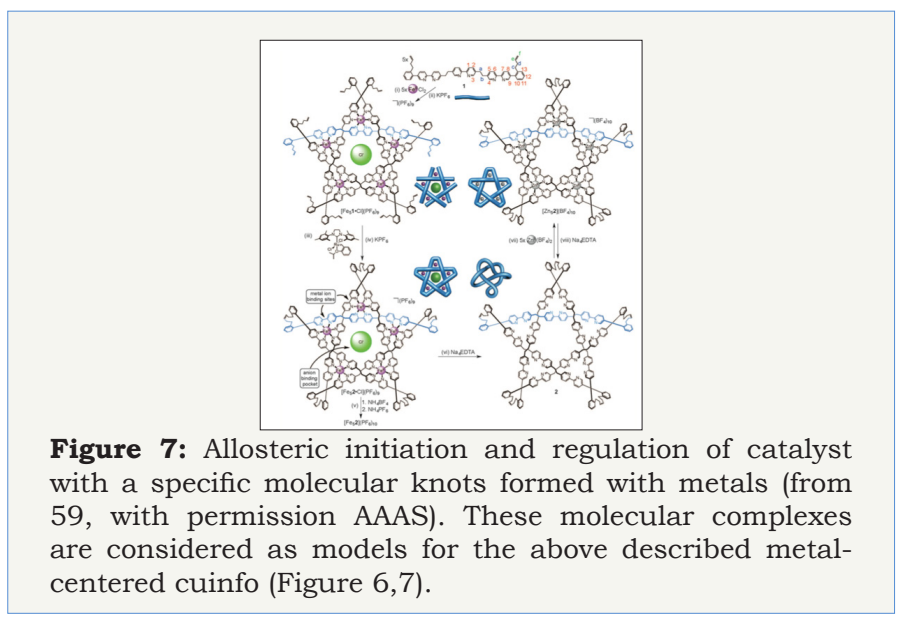

\section{Emotions and feelings}

Table 2: Bio-modulators of physiologic responses, which elicit both physiologic (feelings) and psychic (emotions) responses.

\begin{tabular}{|c|c|c|}
\hline $\begin{array}{c}\text { Chemical } \\
\text { Classification }\end{array}$ & $\begin{array}{c}\text { Physiological Effects } \\
\text { (Feelings) }\end{array}$ & $\begin{array}{c}\text { Psychic } \\
\text { Effects } \\
\text { (Emotions) }\end{array}$ \\
\hline $\begin{array}{c}\text { Neurotransmitters } \\
\text { Biogenic Amines } \\
\text { >10 Amino acids } \\
\text { >75 Neuropeptides } \\
>10 \text { others } \\
\text { (e.g., } \\
\text { endocannabiniods } \\
\text { NO, Ach) } \\
\text { Neurometals } \\
>10 \text { Metal ions } \\
\text { [inclding Zn, Li, } \\
\text { Ca, Co, Cu, Mg, Fe, } \\
\text { Ni, Sr] }\end{array}$ & $\begin{array}{c}\text { Breathing } \\
\text { Blinking } \\
\text { Blood pressure } \\
\text { Coughing } \\
\text { Crying } \\
\text { Dilation of pupil } \\
\text { Drooling } \\
\text { Erection } \\
\text { Evacuation } \\
\text { Fever } \\
\text { Goose-bumps } \\
\text { Heart beat } \\
\text { Itching } \\
\text { Laughing } \\
\text { Orgasm } \\
\text { Pulse } \\
\text { Salivation } \\
\text { Secretion } \\
\text { Spasms } \\
\text { Sweating } \\
\text { Tremors } \\
\text { Vomiting }\end{array}$ & $\begin{array}{c}\text { Anxiety } \\
\text { Aggression } \\
\text { Awareness } \\
\text { Depression } \\
\text { Fear } \\
\text { Hate } \\
\text { Hunger } \\
\text { Joy } \\
\text { Love } \\
\text { Pain } \\
\text { Sadness } \\
\text { Sex drive } \\
\text { Sociability }\end{array}$ \\
\hline
\end{tabular}

To encapsulate: "Emotions" can be considered as remembered "feelings". Terms such as "affective coding" or a "rational emotion" 
are "antinomies" (logical contradictions, Kant 8). Whereas a rational (logical) steps or "demotive" algorithms can be programmed into a binary Turing machine, the emotional (affective) psychic state cannot be encoded, much less programmed into a computer or a robot. Similarly, "neural computation" is not an appropriate term. Facial or voice recognition algorithms do not emulate the emotive psychic states achieved by perceiving familiar face or hearing a familiar voice. Sensations (feelings) are experienced and remembered by the biologic neural net with the aid of neurotransmitters (NTs) (Table 2).

"Objective" simulation without emotions [42-48] is not a real simulation of the "subjective" state experienced by biologic neural nets. It must be recognized that "emotions", the basis for establishing goals or providing value/meaning to the cognitive information (cog-info) processed by biologic neurons, are missing in the binary code formalism, which is inherently "demotive".

\section{Conclusion}

We find ourselves in the inverse position of the boy who cried: "The emperor has no clothes!", as we exclaim: "There are no "naked neurons!" They are swaddled in nECM, which is multi-functional, as it provides structural support and is a hydrogel through which liquids and small molecules diffuse. It also performs as a "memory material", as outlined by the tripartite mechanism which identifies NTs as encoders of emotions.

Awareness of the nECM around neurons and a molecular code for emotions, both missing in the 2 case studies, the IBM chip and the Blue Brain simulation, could lead to better modeling of neural mentation processes relating to neural memory. Such awareness, signaling a "paradigm shift" [60], could influence the financial support for international brain research projects in Europe and the United States [61]. It could also aid the development of "neuromimetic" artifacts and simulations truer to neurobiology and neurochemistry.

\section{Acknowlegement}

(By GM). A memorium to my wife and friend, the artist Georgette Batlle (1940-2009), who enabled my creative efforts in art, science and cuisine. Thanks to friends, Lilly Rivlin (New York, N.Y.) and the late Bill Needle (Eastchester, N.Y.) for their early encouragement and financial support in the period 1980-1984.

Thanks to my companion and tango partner, Karine Ahouva Leopold (Paris, Jerusalem), for clarifying key issues regarding the empathy, feelings and emotions, as well as objective and subjective states.

\section{Conflict of Interest}

a) This work received no funding.

b) GM is a founder of MX Biotech Ltd., involved in developing biotechnologies. c) CG is emeritus professor of $\mathrm{HU}$ but is active in developing and patenting peptide-based tools for surgery and pharmacology.

d) Notwithstanding, the ideas forwarded here are scientifically genuine and presented in good faith, without commercial clouding of the concepts expressed herein.

\section{References}

1. Cajal RY (1911) Histology of the nervous system of man and vertebrae. Oxford University Press, 1995 translation from French.

2. Cerveau \& Conscience (2015) Intelligence emotionelle. Lafontpresse, France.

3. Sweeny MS (2009) Brain: The complete mind. Chapter: New intelligence, National Geographic Publisher, Washington DC, USA

4. Quiroga RQ Fried I, Koch C (2013) Brain cells for grandmother Scientific American, USA, pp. 31-37.

5. Calderone J (2014) 10 big ideas in 10 years of brain science. Scientific American MIND, USA.

6. Zimmer C (2014) The new science of the brain. National Geographic (Cover).

7. LeDoux J (2002) The synaptic self. Penguin Books, London.

8. Kant E (1781) Critique of pure reason.

9. Shiffman D (2012) The nature of code (Magic Book Project).

10. Glickstein M (2006) Golgi and cajal: The neuron doctrine and the $100^{\text {th }}$ anniversary of the 1906 nobel prize. Current Biology 16(5): R147-R151.

11. Garcia LP, Garcia MV, Freire M (2010) The histological slides and drawings of Cajal. Front Neuroanat 4: 1-16.

12. Jones EG (2010) Cajal's debt to Golgi. Brain Res Rev 66(1-2): 83-91.

13. Sotelo C (2011) Camillo Golgi and Santiago Ramon y Cajal: The anatomical organization of the cortex of the cerebellum. Can the neuron doctrine still support our actual knowledge on the cerebellar structural arrangement? Brain Res Rev 66(1-2): 16-34.

14. Schmitt FO (1962) Macromolecular specificity and biological memory. MIT Press, Cambridge, MA, USA 137(3533): 849.

15. Bogoch S (1968) The biochemistry of memory: With an inquiry into the function of brain mucoids. (Oxford University Press, London).

16. Schmitt FO, Samson FE, Irwin LN, Homsy YM (1969) Brain cell microenvironment. Neuroscience Research Program (NRP) Bulletin.

17. Cserr HF (1986) The neuronal environment. Ann NY Acad Sci v. 481.

18. Iwata M, Carlson SS (1993) A large chondroitin sulfate proteoglycan has the characteristics of a general extracellular matrix component of adult brain. J Neurosci 13(1): 195-207.

19. Syková E, Nicholson C (2008) Diffusion in brain extracellular space. Physiol Rev 88(4): 1277-1340.

20. Barros CS, Franco SJ, Muller U (2011) Extracellular matrix: Functions in the nervous system. Cold Spring Harb Perspect Biol 3(1): a00510.

21. Kamali P, Nicholson C (2013) Brain extracellular space: Geometry, matrix and physiologic importance. Basic Clin Neurosci 4(4): 282-286.

22. Di Ventra, Massimiliano, Yuriy VP (2011) Memory materials: a unifying description. Materialstoday 14(12): 584-591.

23. McCulloch WS, Pitts W (1943) A logical calculus of the ideas immanent in nervous activity. Bulletin of Mathematical Biophysics 5(4): 115-133. 
24. Vizi ES, Fekete A, Karoly R, Mike A (2010) Non-synaptic receptors and transporters involved in brain functions and targets of drug treatment. Br J Pharmacol 160(4): 785-809.

25. Guidolina D, Fuxe K, Neria G, Nussdorfer GG, Agnati LF (2007) On the role of receptor-receptor interactions and volume transmission in learning and memory. Brain Res Rev 55(1): 119-133.

26. Agnati LF, Fuxe K (2014) Extracellular-vesicle type of volume transmission and tunnelling-nanotube type of wiring transmission add a new dimension to brain neuro-glial networks. Philos Trans R Soc Lond B Biol Sci 369(1652): 20130505.

27. Anastassiou CA, Perin R, Markram H, Koch C (2011) Ephaptic coupling of cortical neurons. Nature Neuroscience 14: 217-223.

28. Jeffress LA (1967) Cerebral mechanisms in behavior: The Hixon Symposium 1951. Harper Publishing Co., NY, USA.

a. von Neumann J. The general and logical theory of automata, pp. 1-41.

b. McCullogh WS. Why the mind is in the head. pp. 42-57.

29. von Neumann J (1958) The computer and the brain. Yale University Press, New Haven CT, ( $3^{\text {rd }}$ edn), USA, p. 66.

30. a) Merolla PA (2014) A million spiking-neuron integrated circuit with a scalable communication network and interface. Science 345(6197): 668-673.

31. b) Service RF (2014) Cover image and story: The brain chip. Science 345: 614-616.

32. c) Breakthrough of the Year runner-up. (2014) Science 346: 1446.

33. Zhang B, Shi L, Song S (2016) Creating more intelligent robots through brain-inspired computing. Supplement to Science.

34. Markram H (2006) The blue brain project. Nature Reviews Neuroscience 7: 153-160.

35. Markham H (2009) The blue brain project. Utube: TED global lecture.

36. Reimann MW, King JG, Muller EB, Ramaswamy S, Markram H (2015) An algorithm to predict the connectome of neural microcircuits. Front Comput Neurosci 9: 120.

37. Markram H (2015) Reconstruction and simulation of neocortical microcircuitry. Cell 163(2): 456-492.

38. a) Kupferschmidt K (2015) Virtual rat brain fails to impress its critics The blue brain project publishes its simulation of 30,000 neurons. Science 350(6258): 263-264

39. b) (2014) Open message to the European commission concerning the human brain project.

40. Eliasmith C, Stewart TC, Choo X (2012) A large-scale model of the functioning brain. Science 338(6111): 1202-1205.

41. Furber SB (2016) Brain-inspired computing. IET Computers and digital techniques. doi: 10.1049/iet-cdt.2015.0171.

42. Arshavsky YI (2006) The seven "sins" of the Hebbian synapse: Can the hypothesis of synaptic plasticity explain long-term memory consolidation? Progress in Neurobiology 80(3): 99-113.
43. Gallistel CR, King AP (2009) Memory and the Computational Brain Wiley Blackwell, New York, USA.

44. Horn G (2004) Pathways of the past: The imprint of memory. Nature Rev 5(2): 108-120.

45. Carleo G, Troyer M (2017) Solving the quantum many-body problem with artificial neural networks. Science 355(6325): 602-605.

46. Picard R (1997) Affective computing. MIT Press, Boston, USA

47. Goelman D (2007) Emotional Intelligence. Random House, New York, USA.

48. Meshulam M, Winter E, Ben-Shakhar G, Aharon I (2011) Rational emotions. Social Neuroscience, I First, pp. 1-7.

49. Smailes D, Moseley P, Wilkinson S (2015) Affective coding: the emotional dimension of agency. Front Neurosci 9: 142-143.

50. Hasson C (2011) Modeling of emotional mechanisms for an autonomous robot: development and social perspective. PhD Thesis, University of Cergy Pointwise, France.

51. Jauffret A, Cuperlier N, Gaussier P (2015) From grid cells and visual place cells to multimodal place cell: a new robotic architecture. Front Neurorobot 9: 1.

52. Shin H, Kumamoto Y, Gopinath S, Iwasaki A (2016) CD301b+ dendritic cells stimulate tissue-resident memory CD8+ T cells to protect against genital HSV-2. Nat Commun 7: 13346.

53. Surh CD, Sprent J (2008) Homeostasis of naive and memory T cells. Immunity 29(6): 848-862

54. Marx G, Gilon C (2012) The molecular basis of memory. ACS Chemical Neuroscience 3(8): 633-642.

55. Marx G, Gilon C (2013) The molecular basis of memory. MBM Pt 2: The chemistry of the tripartite mechanism. ACS Chemical Neuroscience 4(6): 983-993.

56. Marx G, Gilon C (2014) The molecular basis of memory. MBM Pt 3: Tagging with neurotransmitters (NT). Frontiers in Aging Neuroscience 6: 58

57. Marx G, Gilon C (2016) The molecular basis of neural memory. MBM Pt 4: "Binary"computation vs "multinary"mentation. Neuroscience and Biomedical Engineering 4: 14-24.

58. Marx G, Gilon C (2018) The molecular basis of neural memory. The sins and redemption of neurobiology. J Neurol Neurocrit Care Volume 1(2): 1-7.

59. Marcos V, Stephens AJ, Jaramillo-GJ, Nussbaumer AL, Woltering SL, et al (2016) Allosteric initiation and regulation of catalysis with a molecular knot. Science 352(6293): 1555-1559.

60. Kuhn TS (1970) The Structure of Scientific Revolutions. (2 ${ }^{\text {nd }}$ edn) University of Chicago Press, Chicago IL, USA.

61. Underwood E (2016) International brain projects proposed. Science 352(6283): 277-278.
Creative Commons Attribution 4.0 International License

For possible submissions Click Here

\section{Submit Article}

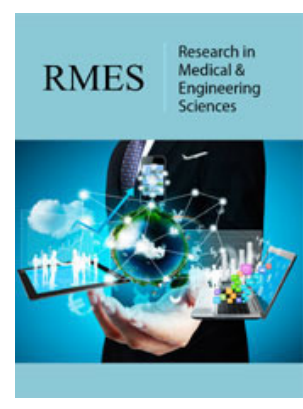

Research in Medical \& Engineering Sciences

Benefits of Publishing with us

- High-level peer review and editorial services

- Freely accessible online immediately upon publication

- Authors retain the copyright to their work

- Licensing it under a Creative Commons license

- Visibility through different online platforms 